\title{
SPubsubúde
}

ARTIGO DE REVISÃO

\section{Recursos eletroterapêuticos para o tratamento do fibroedemageloide}

\section{Electrotherapeutic resources for the treatment of geloid fibro edema}

\section{Vicente Alberto Lima Bessa ${ }^{\circ}$, Maria Fátima de Sousa Bessa ${ }^{\circ}$ \\ ${ }^{1}$ Centro Universitário Celso Lisboa-RJ, Brasil. ${ }^{2}$ Prefeitura do Municipal do Rio de Janeiro. Rio de Janeiro-RJ, Brasil.}

\section{E-mail: vicente.bessa@bol.com.br}

Como citar: Bessa, V.A.L., Bessa, M.F.S. 2019. Recursos eletroterapêuticos para o tratamento do fibroedemageloide, 2, a011.

DOl:https://dx.doi.org/10.31533/pubsau de2.a011

Recebido: 27 set. 2019 .

Revisado e aceito: 28 out. 2019.

Conflito de interesse: os autores declaram, em relação aos produtos e companhias descritos nesse artigo, não ter interesses associativos, comerciais, de propriedade ou financeiros que representem conflito de interesse.

Licenciamento: Este artigo é publicado na modalidade Acesso Aberto sob a licença Creative Commons Atribuição 4.0 (CC-BY 4.0).
R e s u m o. Introdução: O estudo teve como objetivo investigar os principais recursos eletroterapêuticos utilizados no tratamento do fibroedemageloide. As informações obtidas nas bases de dados PubMed, Dovepress, Scielo, LILACS, ScienceDirect foram escolhidas e organizadas no formato de uma revisão descritiva sobre as alterações do fibroedemageloide na pele e os recursos eletroterapêuticos envolvidos no seu tratamento. Revisão: fibroedemageloide representa uma disfunção estética e de saúde, por isso a eletroterapia é muito procurada a fim de melhorar o aspecto corporal ou mesmo prevenir a manifestação de qualquer alteração. Discussão: Foi realizada uma análise dos principais tratamentos eletroterapêuticos para o fibroedemageloide. 4 . Considerações finais: Os tratamentos eletroterapêuticos mais recomendados pelos seus resultados satisfatórios são: carboxiterapia, radiofrequência, ultrassom, terapia por ondas de choque e terapias combinadas.

P a l a v r a s - c h a ve : paniculose, fibroedemageloide, celulite.

\begin{abstract}
A b stract . Introduction: The study aimed to investigate the main electrotherapeutic resources used in the treatment of geloid fibro edema. Information obtained from the databases PubMed, Dovepress, Scielo, LILACS, ScienceDirect were chosen and organized in the format of a descriptive review about the alterations of geloid fibro edema in the skin and the electrotherapeutic resources involved in its treatment.

Review: The geloid fibro edema represents a health and aesthetic dysfunction, so electrotherapy is much sought in order to improve the body aspect or even prevent the manifestation of any alteration.
\end{abstract}


Discussion: An analysis of the main electrotherapeutic treatments for geloid fibro edema was performed.

Final remarks: The most recommended electrotherapeutic treatments for its satisfactory results are: carboxytherapy, radiofrequency, ultrasound, shock wave therapy and combined therapies.

K e y w o r d s : paniculosis, geloid fibro edema, cellulite.

\section{INTRODUÇÃO}

É sabido que num mundo da Era Digital, no qual impera o registro de imagens e sua divulgação por meio virtual (Twitter, Facebook, Whatsapp, Instagram, etc.), a estética facial, capilar e corporal tem sido cada vez mais valorizada. Pode-se afirmar que grande parte das mulheres tem buscado algum tipo de procedimento estético para melhorar a sua aparência ou para solucionar seus problemas relacionados à beleza. O fibroedemageloide (FEG) tem um impacto significativo na estética corporal, principalmente em mulheres, visto que pode até propiciar uma diminuição na autoestima.

Esse fato é evidente quando se constata que o FEG afeta um percentual muito elevado de mulheres póspúberes, cerca de 85 a $98 \%$, independemente da etnia. Logo, ele é uma disfunção de interesse dos profissionais de saúde e beleza. Conquanto possa afetar quaisquer regiões do corpo que tenha tecido adiposo subcutâneo, ele tem sua maior incidência na parte externa e superior das coxas e na parte posterior das coxas e nádegas (Treu et al., 2009).

O fibroedemageloide é uma disfunção inflamatória, complexa e multifatorial que afeta o tecido conjuntivo subcutâneo com característica de uma infiltração edematosa acompanhada de polimerização da substância fundamental que, infiltra-se nas tramas e produz uma reação fibrótica consecutiva. E graças à compreensão da etiologia e fisiopatologia do FEG, houve um avanço no arsenal eletroterapêutico aumentando os recursos para abrandar ou corrigir algumas imperfeições que atingem a derme profunda e o tecido adiposo superficial com mais segurança. Houve também uma evolução nos procedimentos de avaliação e acompanhamento do tratamento do FEG, como o uso de imagens ultrassonográficas, a criação da escala de gravidade fotonumérica, etc.

Considerando a grande incidência estatística do FEG e sua repercussão orgânica e emocional nos portadores, foi realizado um estudo concernente aos principais recursos eletroterapêuticos que são elegíveis no tratamento do fibroedemageloide. Para tanto, buscou-se informações através dos descritores: paniculose, fibroedemageloide e celulite por meio das bases de dados da PubMed, Dovepress, Scielo, 
LILACS, ScienceDirect. Os dados obtidos foram escolhidos e organizados no formato de uma revisão descritiva sobre as alterações do FEG na pele e os recursos eletroterapêuticos envolvidos no seu tratamento.

O estudo teve como objetivo geral investigar os principais recursos eletroterapêuticos utilizados no tratamento do fibroedemageloide. E como objetivos específicos: descrever a fisiopatologia do fibroedemageloide; identificar os graus do fibroedemageloide e condutas para examiná-los; e analisar benefícios dos recursos eletroterapêuticos mais utilizados no tratamento do fibroedemageloide.

\section{REVISÃO}

O fibroedemageloide tem importância social em virtude das disfunções estéticas que promovem um forte impacto psicológico, sobretudo quando afeta áreas extensas ou proporções exuberantes (Barata, 2015), por isso merece atenção terapêutica e estética. Há várias nomenclaturas para designar o fibroedemageloide, tais como: linfóstase cutânea regional, lipodistrofiaginoide, hidrolipodistrofia ginoide, paniculopatia edematofibroesclerosa, no entanto a mais conhecida é celulite.

Foi na França, em torno de 1920, que Alquier e Paviot descreveram o termo celulite acreditando que ela seria uma distrofia celular complexa não inflamatória do tecido mesenquimatoso, cuja etiologia estaria centrada numa disfunção no metabolismo da água em resposta a agressão de ordem traumática, tóxica ou endócrina, acrescida da saturação do tecido adjacente por fluido intersticial. Todavia, Lagèse, em 1928, confirmou a existência de soro no espaço intersticial, fibrose e retração esclerótica, fato este que contesta o termo anterior (Mendonça \& Ramires, 2016).

É mister destacar que a celulite ao longo da sua história passou a ter várias denominações na tentativa de melhor definí-la e cada pesquisador defendeu a terminologia por ele adotada. Em 1977, Binazzi denominou celulite como paniculopatia edematofibroesclerosa (PEFE) ou paniculose; em 1991, Curri a denominou lipoesclerose nodular; em 1992, Ciporkin e Paschoal utilizaram o termo lipodistrofiaginoide (LDG) ou lipodistrofia localizada (Coutinho \& Bravo, 2018, Siqueira, 2014). No entanto, outros termos foram adotados, tais como: fibroedemageloide, linfóstase cutânea regional, mesenquimatose, lipoesclerose e dermatopaniculose vasculopática (Siqueira, 2014). Não obstante, a terminologia que é considerada mais adequada na descrição da disfunção é fibroedemageloide (FEG), pois ele relata precisamente as alterações que acontecem na pele (Coutinho \& Bravo, 2018, Borges \& Scorza, 2016). O termo celulite é muito popular na mídia e no meio estético, porém chamar o fibroedemageloide de celulite é errado, pois esta é uma infecção que se não tratada pode se tornar grave 
para saúde do seu portador. Logo, ela não tem nenhuma relação com a disfunção estética na qual este estudo foi desenvolvido (Ramos, 2018).

É sabido que o termo celulite se referir ao processo infeccioso bacteriano do tecido subcutâneo que se caracteriza pela presença de uma área com edema de bordas mal definidas e dolorosas (Cavaleri et al., 2017). Dentre as bactérias mais frequentes para infectar a derme profunda e o tecido subcutâneo estão o S. aureus e estreptococos do grupo A. Apesar disso, outras bactérias também podem causar a infecção, tais como: Haemophilus influenzae e bacilos Gram-negativos, além da possibilidade da infecção por fungos como Cryptococcus neoformans (Souza, 2003).

\section{DISCUSSÃO}

É preciso ressaltar que embora equivocado o termo celulite persiste e é empregado pelos profissionais de saúde por sua popularização, porém é sabido a sua diferença. Neste estudo, optou-se pelo termo fibroedemageloide que é uma infiltração edematofibroesclerosa no tecido conjuntivo, no qual há uma congestão de fluídos associada às alterações microcirculatórias (Bertozzo, 2016).

Portanto, o presente estudo tratou apenas das celulites não infecciosas e de interesse da estética corporal. Logo, o conceito a ser considerado neste estudo é de que o FEG é uma disfunção estética que afeta os adipócitos da tela subcutânea (Kede \& Sabatovich, 2015). Nele há um desequilíbrio do metabolismo, na microcirculação e nas fibras de sustentação da tela subcutânea e pode-se perceber o aspecto ondulado da epiderme, tipo “casca de laranja”, em algumas regiões do corpo.

O FEG é um distúrbio prevalente em cerca de 90\% das mulheres em todo o planeta e é mais raro nos homens, pois eles apresentam uma diferença na arquitetura subcutânea em relação às mulheres (Coutinho \& Bravo, 2018). É sabido que os adipócitos são organizados em lóbulos, os quais são separados uns dos outros por septos de tecido conjuntivo que ligam a derme reticular à fáscia muscular. Nos homens os septos são mais espessos e estão dispostos em diagonal, porém nas mulheres eles são mais finos e em perpendicular (Seeley et al., 2011). Essas características fazem com o que nos homens, quando ocorre aumento de tecido adiposo sob a pele, este se projete para o fundo. Porém, nas mulheres quando ocorre o aumento do tecido gorduroso, ele se projeta para fora, por isso as irregularidades são mais visíveis na superfície da pele da mulher.

Outro fato notório é o resultado de um estudo de ressonância magnética nuclear (RMN) que examinou morfologicamente o tecido adiposo subcutâneo que permitiu evidências das diferenças estruturais relacionadas ao sexo provando a relação genética da "hérnia" dos lobos adiposos na derme reticular em mulheres com FEG. Outros dois achados 
foram: à ausência de correlação direta entre o índice de massa corporal e o advento de irregularidades na superfície cutânea em mulheres com IMC acima de 30; e a identificação da relação entre a magreza e frouxidão constitucional nas bandas interlobulares fibrosas, logo as propriedades viscoelásticas da pele estariam alteradas. No estudo, os autores concluíram que a análise da RMN da arquitetura em 3D de septos fibrosos não podem ser simplesmente modelados como planos perpendiculares para mulheres e planos inclinados a 45 graus para homens. Outra inferência foi que não se confirmou o aumento do teor de água no tecido adiposo de mulheres com FEG, conforme sugerido por outros autores, exceto se esta água estivesse localizada nos septos conjuntivos. (Querleux et al., 2002).

É sabido que os hormônios estrogênio e progesterona propiciam o aumento no volume dos adipócitos, ao passo que a testosterona diminui o volume dos mesmos (Guerreiro, 2016). Outro fator importante é a alteração hormonal após a puberdade, durante as gestações ou no uso de contraceptivos orais que aumentam a retenção de água, sobretudo no tecido gorduroso nas coxas externas, coxas posteriores e nádegas (Silva et al., 2017).

A etiologia do FEG é complexa e multifatorial e possui alta prevalência em adultas jovens, sem nenhuma morbidade, porém gera descontentamento e impacto negativo na qualidade de vida (Pianez et al., 2016). Os principais fatores que favorecem o desenvolvimento do FEG são: hiperestrogênismo (principal fator desencadeante), hereditariedade, sexo feminino, etnia e biotipo corporal. Nada obstante, há fatores que agravam o FEG, tais como: sedentarismo, medicamentos, gestação, estresse e hábitos alimentares inadequados (Sartori et al., 2017).

Embora, o FEG seja pouco frequente nos homens, quando surge afeta aqueles de meia-idade com tendência a retenção de líquidos (Guerreiro, 2016). O FEG, em geral, aparece após a puberdade e não tem exclusividade étnica, ainda que seja mais comum entre as pessoas de pele branca. Quanto à etiologia, o FEG é considerado uma disfunção multifatorial e dentre as principais estão: predisposição genética e familiar, desequilíbrios hormonais e distúrbios circulatórios (Sahd, 2019; Bosi, 2018). Outras causas conhecidas são: configuração dos septos no tecido subdérmico e diminuição da circulação linfática (Bosi, 2018) e medicamentos, sedentarismo, dieta não balanceada e gravidez (Sahd, 2019). Ele ainda pode ser agravado quando associado a quadros de obesidade, posturas corporais, tabagismo, alcoolismo e estresse. (Borges \& Scorza, 2016).

Sabe-se, portanto, que a fisiopatologia do FEG se relaciona a um conjunto de modificações da arquitetura do tecido adiposo subcutâneo e da microcirculação local, especificamente: alterações vasculares, 
deformações da matriz intersticial que rodeia os adipócitos e fatores inflamatórios (Guerreiro, 2016).

As alterações vasculares do FEG comprometem a microcirculação sanguínea o que diminui o aporte de oxigenação e nutrição tecidual, além de prejudicar a excreção de alguns produtos do metabolismo (Figura 1). O comprometimento vascular sanguíneo pode propiciar alteração na circulação linfática, o que pode gerar um acúmulo de fluidos. Assim sendo, haverá uma transudação plasmática pericapilar e formação de feixes de colágeno que podem aumentar de espessura de forma progressiva entorno dos adipócitos. Logo, há formação de micronódulos o que atrapalha a circulação sanguínea e estes formam macronódulos devido à aposição do material de colágeno que se torna esclerótico. Os macronódulos são palpáveis e causam a irregularidade da superfície da pele (Barata, 2015; Terranova et al., 2006).

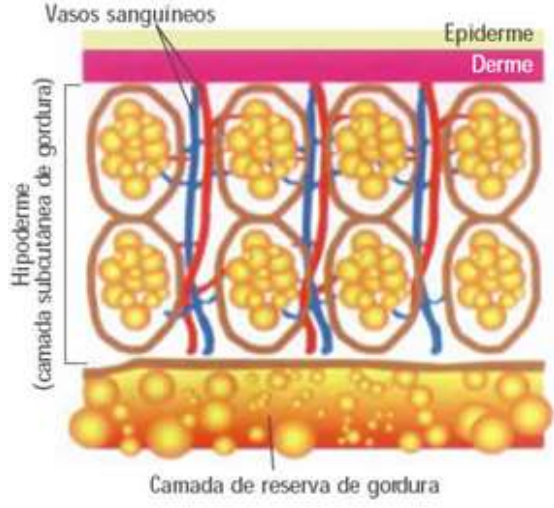

Pele bem vascularizada - normal

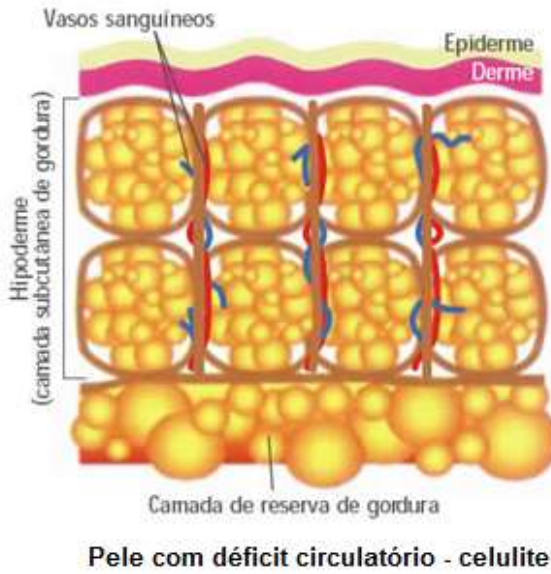

Pele com déficit circulatório - celulite

Figura 1. Compressão do sistema circulatório pelo tecido adiposo e formação do FEG.

Fonte: BORGES \& SCORZA, 2016, p.609.

A matriz intersticial que rodeia os adipócitos é formada por fibroblastos que sintetizam colágeno, elastina, proteoglicanos, glicosaminoglicanos e glicoproteínas e estas proteínas conferem elasticidade, suporte ao tecido cutâneo e a difusão dos nutrientes e metabolitos oriundos da circulação. Todavia no FEG, os glicosaminoglicanos sofrem um processo de hiperpolimerização, aumentando o seu poder hidrofílico e a pressão osmótica intersticial. O aumento anormal da hidrofilia tecidual interfere nas trocas celulares devido à compressão de vasos e com correspondente hipóxia tecidual. Em exame histológico, pode-se verificar sinais de ativação de fibroblastos, alterações nas paredes dos microvasos, além de rarefação de colágeno subepidérmico e fibras elásticas (Barata, 2015; Terranova et al., 2006).

O FEG era conceituado como uma disfunção do tecido conjuntivo subcutâneo com característica de uma infiltração edematosa, não inflamatória acompanhado de polimerização da substância 
fundamental. Acrescida da infiltração da polimerização nas tramas que pode produzir uma reação fibrótica (Bergesch, 2019; Menezes et al., 2010; Bacelar \& Vieira, 2006; Guirro \& Guirro, 2004). No entanto, o fato de ser uma disfunção não inflamatória tem sido contestado, pois há estudos com biópsia que evidenciam a presença de leucócitos polimorfonucleares, linfócitos, eosinófilos e macrófagos adjacentes aos septos. Esse fato ratifica a inflamação que resultaria em ruptura nos adipócitos e atrofia cutânea (Bergesch, 2019). Um estudo denominado “Celulite: fatos e ficção”, realizado por Kligman em 1979, já identificou o processo inflamatório celular crônico com macrófagos e linfócitos nos septos fibrosos após análise feita por biópsia de pele. Ele concluiu que a inflamação leve seria resultado dos septos comprometidos e proporcionaria a lise dos adipócitos e atrofia cutânea (Afonso et al., 2010). Assim sendo, ultimamente, o FEG já é considerado uma disfunção inflamatória.

Os sintomas do FEG variam de acordo com o grau no qual se encontra. No estágio inicial, o FEG é assintomático, no entanto no estágio mais avançado a região fica fria, endurecida, dolorosa, sensível à palpação e com aspecto ondulado da epiderme, tipo “casca de laranja”. Para identificá-lo é possível fazer três testes bem simples e rápidos, a saber: teste da casca de laranja, o qual consiste em pedir ao cliente que faça uma contração voluntária na musculatura no local a ser examinado; o teste de preensão, que consiste em apertar entre os dedos a região examinada; e o de palpação e rolamento entre os dedos (Ramos, 2018).

Quanto à avaliação do FEG, tem-se inspeção, palpação, classificação na escala de gravidade da celulite, exame antropométrico, cálculo do IMC, termografia e a bioimpedância. Outros exames também podem ser utilizados, porém não são muito frequentes, tais como: monofilamentos de Semmmes-Weinstein, xerografia, ecografia bidimensional, ressonância nuclear magnética, ultrassonografia de alta resolução, exames anatomopatológicos e laboratoriais (Borges \& Scorza, 2016).

Terranova et al. (2006) elaboram uma tabela que estabelece os estágios da FEG e sua relação com a observação clínica e aspectos histológicos e histoquímicos e sua patogenia (Tabela 1). A classificação é útil para avaliar o cliente e determinar o estágio do FEG.

Outra forma de avaliar é usar a escala de gravidade fotonumérica (Figura 2) que foi desenvolvida e validada por dermatologistas brasileiras, a qual se baseou em fotografias padronizadas de 55 pacientes com FEG para identificar cinco principais aspectos morfológicos: número e profundidade de depressões, aspecto clínico das áreas elevadas do FEG, presença de lesões elevadas, presença de flacidez e graus da classificação de Nurnberger e Müller. A escala define com maior precisão os graus de FEG, considerando os detalhes clínicos mais relevantes para cada cliente. Cada característica recebeu um 
número que varia de 0 a 3 , sendo que a soma pode chegar no máximo a 15 pontos. Se o FEG somar de 1 a 5 pontos é do tipo leve, de 6 a 10 é moderado e de 11 a 15 é grave. Portanto, a Escala Fotonumérica consiste em um exame criado para classificar o FEG de forma objetiva e internacionalmente (Hexsel et al., 2009).

Tabela 1. Estágios da FEG.

Estágio Classificação clínica Patogênese Histologia e hidtoquímica

\begin{tabular}{|c|c|c|c|}
\hline I & $\begin{array}{c}\text { Pele pálida e } \\
\text { pastosa }\end{array}$ & $\begin{array}{c}\text { Má distribuição } \\
\text { microcirculatória e defeito } \\
\text { vasomotor }\end{array}$ & $\begin{array}{c}\text { Lipoedema, } \\
\text { anisopoiquilocitose e rotura } \\
\text { da membrana }\end{array}$ \\
\hline II & $\begin{array}{l}\text { Hiperelasticidade } \\
\text { cutânea, } \\
\text { hipertermia e } \\
\text { parestesia }\end{array}$ & $\begin{array}{c}\text { Estase, ectasia de microvaso, } \\
\text { hipovolemia anormal e } \\
\text { hipóxia zonal }\end{array}$ & $\begin{array}{l}\text { Manifestações adipócitas } \\
\text { regressivas, dilatação de } \\
\text { microvaso maciça e } \\
\text { fibrilopoiese }\end{array}$ \\
\hline III & $\begin{array}{c}\text { Pele de casca de } \\
\text { laranja (manchas de } \\
\text { hiperqueratose), } \\
\text { pequenos nódulos } \\
\text { palpáveis }\end{array}$ & $\begin{array}{c}\text { Redução do fluxo capilar e } \\
\text { aumento nas áreas de relativa } \\
\text { hipóxia }\end{array}$ & $\begin{array}{l}\text { Neofibrinogênese e } \\
\text { adipócitos degenerados } \\
\text { encapsulados em } \\
\text { micronódulos }\end{array}$ \\
\hline IV & Nódulos dolorosos & $\begin{array}{l}\text { Estase, hipovolemia, } \\
\text { telangiectasia e } \\
\text { microvaricosidade }\end{array}$ & $\begin{array}{c}\text { Pacotes de colágeno } \\
\text { esclerótico de conexão ao } \\
\text { redor de } \\
\text { macronódulos. Fenômenos } \\
\text { distróficos locais da derme e } \\
\text { da epiderme }\end{array}$ \\
\hline
\end{tabular}

Fonte: Terranova et al., 2006.

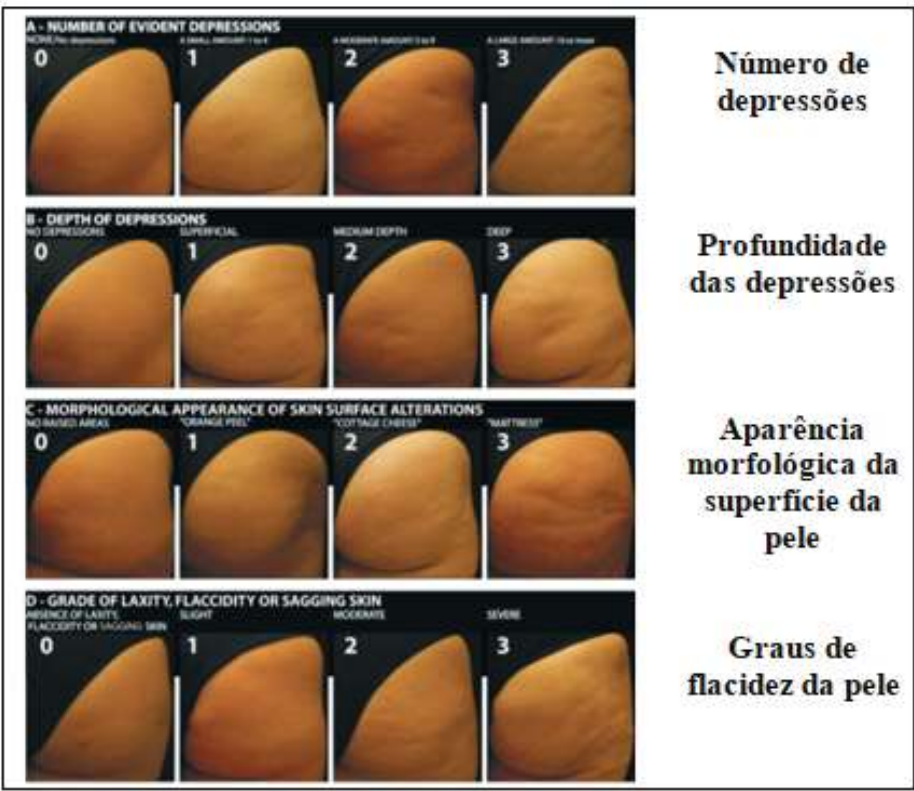

Figura 2. Escala Fotonumérica. Fonte: Hexsel et al., 2009. 
Muitos tratamentos têm sido propostos para o FEG, desde conduta de dieta balanceada, prática de exercícios e tratamentos estéticos específicos, tais como: uso de cosméticos associados ou não a condutas termoterapêuticas, fototerapêuticas, eletroterapêuticas e massoterapia. Dentre os procedimentos eletroterapêuticos, há destaque para a carboxiterapia, radiofrequência, ultrassom, terapia extracorpórea por ondas de choque e terapias combinadas. Todavia, o uso apenas de equipamentos não garante o sucesso absoluto do tratamento e nem a sua durabilidade, logo é importante a combinação de tratamentos e adesão do cliente à mudança de hábitos e de estilo de vida mais saudáveis. É recomendado que a pessoa invista em hábitos saudáveis como beber de preferência água e praticar exercícios aeróbicos e diminuir a ingestão de sódio, alimentos com gorduras trans, cis e saturadas, excesso de carboidratos, não fumar e evitar uso de anticoncepcionais e bebidas alcoólicas.

É indispensável destacar que a avaliação do FEG e seu tratamento têm exigido o emprego de tecnologias que tornam os resultados mais efetivos e de menor custo (Pianez et al., 2016). Dentre os recursos eletroterapêuticos viáveis e eficientes para tratar o FEG, tem-se a terapia com dióxido de carbono (CO2) ou carboxiterapia, a qual não tem apresentado efeitos colaterais graves e tem se mostrado de grande eficiência estética a saúde da mulher. Além de tratar o FEG, ela também tem efeito sobre a diminuição de peso durante o tratamento e, desta forma, também auxilia no aumento da autoestima dos clientes (Silva et al., 2017).

É sabido que a carboxiterapia teve sua origem na França em 1932 e consistiu na administração de $\mathrm{CO} 2$ com proposta de tratamento percutâneo de arteriopatia e úlcera. Seus resultados satisfatórios propiciaram novos estudos, dentre eles o tratamento de adiposidade localizada que também demonstrou possíveis efeitos lipolíticos. Para investigar a eficácia da carboxiterapia no tratamento do FEG nas áreas das nádegas e posterior da coxa foi desenvolvido o estudo piloto sobre a "Efetividade da carboxiterapia no tratamento da celulite em mulheres saudáveis”. Para tanto, 10 voluntárias foram submetidas a 8 sessões de carboxiterapia com intervalo de uma semana. Para avaliar o FEG foram realizadas fotografias digitais padronizadas além de imagens panorâmicas por ultrassonografia antes do tratamento e uma semana após a última sessão. A pesquisa trouxe resultados significativos na redução do FEG grau III para II que puderam ser comprovadas por análise das imagens ultrassonográficas, as quais indicaram melhor organização das linhas fibrosas e redução do tecido adiposo entre a pele e os músculos nas regiões tratadas (Pianez et al., 2016).

O dióxido de carbono infundido pode propiciar o aumento do fluxo sanguíneo e consequente hiperoxigenação tecidual, além do estímulo à 
lipólise e a lise adipocitária. A aplicação para tratar o FEG é feita de forma hipodérmica, ou seja, a agulha é introduzida diretamente no tecido subcutâneo, utilizando um fluxo alto, a partir de $150 \mathrm{ml} / \mathrm{min}$ a $180 \mathrm{ml} / \mathrm{min}$, sendo recomendadas duas sessões por semana (Borges \& Scorza, 2016).

Outro tratamento aconselhado para o FEG é a radiofrequência que consiste num campo eletromagnético com frequência muito variável, de $3 \mathrm{kHz}$ a $300 \mathrm{GHz}$. Para verificar a eficácia da radiofrequência foi desenvolvido um estudo de campo com dez voluntárias com FEG nos graus II e III na região de glúteo. As participantes foram avaliadas através de anamnese, inspeção, teste de casca de laranja, cirtometria da região de flancos, quadril e culotes e fotografias da região de glúteo para posterior comparação. Elas foram submetidas a dez sessões de radiofrequência com o equipamento Spectra G1 (TONEDERM), com 24 horas de intervalo, no mínimo. O estudo concluiu que o efeito produzido pelo calor endógeno da radiofrequência contribuiu para a redução no grau do FEG, além de melhora no aspecto da pele na região de glútea (Sartori et al., 2017).

É preciso salientar que a radiofrequência é um tipo de energia que penetra ao nível das células da epiderme, derme e tecido subcutâneo e inclusive nas células musculares. A energia eletromagnética ao penetrar nos tecidos encontra resistência e seu atrito eleva a temperatura. $\mathrm{O}$ aumento da temperatura tissular propicia fenômenos de vasodilatação e, desta forma, aumenta a oxigenação, trofismo tissular e a reabsorção dos fluídos intercelulares excessivos (toxinas e radicais livres). Ela ainda possibilita a melhora da síntese de fibras elásticas e ação de lipólise homeostática, isto é, degradação de lipídios em ácidos graxos e glicerol e que ocorre no tecido adiposo (Cavaleri et al., 2017). A radiofrequência gera uma cascata inflamatória que estimula a síntese de colágeno, logo conduz ao espessamento da derme, sustentação e firmeza a pele (Sartori et al., 2017). Esses fenômenos melhoram o aspecto do FEG e as condições gerais da pele e tecido subcutâneo.

Uma pesquisa prospectiva, comparativa, tipo antes e depois, não randomizada e sem grupo-controle foi realizada em oito voluntárias, na faixa etária de 28 e 45 anos, com FEG nas nádegas e coxas com graus II e III (Escala Nurnberger-Muller). O estudo objetivou avaliar a segurança e eficácia da radiofrequência unipolar no tratamento do FEG e, para tanto, as voluntárias foram avaliadas por clinicofotográfica, exames laboratoriais e ultrassonografia antes, durante e 30 dias após termo da última sessão. Elas foram submetidas a quatro sessões de radiofrequência unipolar com intervalos quinzenais e foram orientadas a não mudarem seus hábitos alimentares e nem utilizarem medicamentos que possam melhorar o estado da pele ou do FEG. Durante o tratamento, utilizou-se óleo mineral para deslizamento da 
ponteira unipolar, a qual permaneceu em total contato com a pele, em posição perpendicular, com movimentos circulares, horizontais e verticais por 10 minutos em cada $10 \mathrm{~cm}^{2}$, com intervalo de 5 a 10 segundos a cada 30 segundos. Foi aplicada a energia de acordo com o IMC das voluntárias, sendo selecionado energia inicial de $180 \mathrm{~W}$ para IMC entre 20 e 22 e $220 \mathrm{~W}$ para IMC de 22 a 25 . Após se alcançar $40^{\circ} \mathrm{C}$ a energia foi diminuída em $10 \%$ a cada ciclo de 30 segundos, porém sempre se mantendo a temperatura entre 39 e $41^{\circ} \mathrm{C}$. Os resultados foram: melhora do tônus da pele, diminuindo o aspecto ondulado da pele, aumento da espessura dérmica e redução do número de herniações do tecido subcutâneo constatada pela análise das imagens ultrassonográficas. Não houve alterações nas taxas séricas de colesterol, HDL, LDL, VLDL ou triglicerídeos em nenhuma etapa da avaliação. Ao final do estudo, pode-se concluir que a radiofrequência é um método seguro, confiável e eficiente para tratar FEG nas nádegas e coxas e com resultados satisfatórios em apenas um mês após tratamento (Bravo et al., 2013).

Como a temperatura do tratamento para o FEG está acima de $40^{\circ} \mathrm{C}$ é possível se estimular a produção de colágeno nas traves fibróticas e agravar o quadro clínico do cliente, por isso é aconselhável que em seguida, ainda com a pele aquecida, seja aplicado a vacuoterapia. E quanto à periodicidade do tratamento, sugere-se duas a três vezes por semana, em dias alternados, de acordo com a temperatura adotada (Borges \& Scorza, 2016).

Mais uma alternativa de tratamento do FEG é a terapia por ultrassom. Há um estudo piloto que objetivou coletar resultados preliminares concernentes a eficácia do ultrassom na diminuição do FEG na região glútea de mulheres jovens e sedentárias. A metodologia consistiu em dividir às cinco voluntárias com grau II de FEG em dois grupos e aplicou-se fonoforese utilizado um acoplante a base de hera, Centella asiática e castanha da índia num aparelho com frequência de 3 $\mathrm{MHz}$ no modo contínuo, fabricado pela Chatanooga Group - Encore Medical. O primeiro grupo foi submetido ao tratamento com transdutor com ERA de $8,5 \mathrm{~cm}^{2}$ e intensidade de 1,1 watts $/ \mathrm{cm}^{2}$ e o segundo com ERA de $4 \mathrm{~cm}^{2}$ e intensidade de 1,5 watts/cm2, sendo atribuído 1 minuto por ERA. Todas as participantes foram avaliadas quanto ao grau de FEG e submetidas a 16 sessões, 4 vezes por semana. Os resultados não foram muito promissores, pois somente uma das cinco participantes obteve resposta satisfatória. Inferiu-se que os resultados insatisfatórios estariam relacionados à inconstância do nível de contração muscular da região glútea (Federico et al., 2006).

Todavia, outro estudo mais recente que objetivou comparar os resultados e a eficácia do ultrassom terapêutico de $3 \mathrm{MHz}$ no tratamento do FEG em glúteos obteve resultados um pouco mais satisfatórios. A 
pesquisa do tipo longitudinal e com variáveis quantitativas e qualitativas consistiu em submeter 20 voluntárias a fonoforese. Elas eram sedentárias, na faixa de 20 a 30 anos, faziam uso de contraceptivos orais e apresentavam FEG na região glútea. Para analisar os resultados, as participantes foram previamente avaliadas por ficha de avaliação, registro fotográfico, perimetria, teste de casca de laranja, classificação do grau do FEG e escala de satisfação pessoal. Todas foram tratadas com 10 sessões com o equipamento de ultrassom da KLD, na frequência de $3 \mathrm{MHz}$, modo contínuo e intensidade de 2,0 watts/cm. Utilizou-se o gel mobilizador reducxel slin com princípios ativos da empresa Adcos e o tempo de aplicação foi de 45 minutos e 2 vezes na semana. O estudo foi concluído com 19 participantes, pois uma não deu prosseguimento até o final, sendo descartada. Os resultados permitiram inferir que houve melhora no aspecto geral do glúteo, satisfação pessoal com aumento da autoestima, porém sem resultados excelentes. Visto que apenas $21,05 \%$ das voluntárias tiveram resultados satisfatórios, $47,37 \%$ resultados discretos e $31,58 \%$ não obtiveram resultados (Cappellazz et al., 2015).

Um outro estudo sobre ultrassom foi realizado através de revisão descritiva da literatura sobre o uso de formulações cosmética contendo cafeína e extrato de Centelha asiática associados ou não ao ultrassom para o tratamento do FEG, o qual foi apresentado no $6^{\circ}$ Congresso Internacional em Saúde em 2019. A pesquisa buscou publicação dos últimos dez anos nas bases de dados Scielo, LILACS, PubMed, ScienceDirect e Portal da CAPES através dos descritores: fibroedemageloide, celulite, Centella asiática, cafeína, ultrassom, permeação cutânea. Pode-se concluir que há evidências dos benefícios do efeito da cafeína e do extrato de Centella asiática no tratamento do FEG. Porém, há registros de que a cafeína, devido as suas características químicas, não apresenta uma boa permeação nas camadas mais profundas da pele, local no qual deveria exercer o seu efeito. E justamente a associação dos cosméticos com o ultrassom seria a ferramenta ímpar para incrementar a permeação e aumentar a eficiência do tratamento (Albrecht et al., 2019).

A seguir, tem-se um quadro que foi elaborado por Sahd (2019), no qual ela apresenta de forma resumida os principais procedimentos fototermoeletroterapêuticos empregados na estética corporal e suas ações (Tabela 2). O quadro foi adaptado para apresentar apenas os procedimentos usados no FEG.

A terapia extracorpórea por ondas de choque tem sido amplamente utilizada na estética e seus benefícios tem sido foco de estudo. Essa terapia utiliza uma onda de pressão acústica que pode ser produzida em qualquer meio elástico, tais como ar, água ou substância sólida. O equipamento emite uma sequência de pulsos mecânicos sonoros de alta 
energia e alto gradiente de pressão. A energia penetra no tecido e promove a cavitação que é capaz de produzir reações bioquímicas intracelulares, neoangiogênese e celularidade, fenômenos estes que estimulam o processo regenerativo tecidual.

Tabela 2. Métodos e técnicas usados para tratar o FEG (Adaptado).

\begin{tabular}{|c|c|}
\hline Tratamento & Ação \\
\hline Carboxiterapia & $\begin{array}{l}\text { A técnica é realizada com auxílio de uma fina agulha em um } \\
\text { cilindro de gás carbônico }\left(\mathrm{CO}_{2}\right) \text {. A agulha é inserida no tecido } \\
\text { subcutâneo, e o cilindro regula a vasão de } \mathrm{CO}_{2} \text { injetado na } \\
\text { região escolhida para o tratamento. No metabolismo do corpo, } \\
\text { quando uma quantidade maior de gás } \mathrm{CO}_{2} \text { é injetada nas } \\
\text { células, ele age para equilibrar a quantidade de } \mathrm{CO}_{2} \text { e de } \\
\text { oxigênio nas estruturas, levando ao aumento da circulação } \\
\text { sanguínea, proporcionando maior firmeza e sustentação da } \\
\text { pele. }\end{array}$ \\
\hline Intradermoterapia & $\begin{array}{l}\text { Também conhecido como mesoterapia, esse método consiste } \\
\text { na aplicação por intermédio de uma agulha fina, que injetará } \\
\text { uma pequena quantidade da substância no tecido subcutâneo, } \\
\text { proporcionando uma alta concentração de fármaco no local, } \\
\text { potencializando a absorção pelos tecidos e promovendo } \\
\text { resultados mais rápidos e potentes. Os medicamentos } \\
\text { utilizados são substâncias lipolíticas, que também podem ser } \\
\text { usadas em combinações com outros ativos, como } \\
\text { Dimetilaminoetanol (DMAE), vitamina C, silício e ácido } \\
\text { hialurônico. }\end{array}$ \\
\hline $\begin{array}{l}\text { Smooth Shapes } \\
\text { (laser de diodo aliado a } \\
\text { massagem suave e } \\
\text { vácuo) }\end{array}$ & $\begin{array}{l}\text { Esse método utiliza luz infravermelha para eliminar a gordura } \\
\text { que se encontra dentro das células, além de um sistema de } \\
\text { massagem de sucção e rolamento para drenagem linfática. O } \\
\text { calor produzido e a massagem estimulam a regeneração do } \\
\text { colágeno, colaborando com a diminuição de edemas causados } \\
\text { por fibras de colágeno endurecidas. }\end{array}$ \\
\hline $\begin{array}{l}\text { Ultra Accent XL } \\
\text { (radiofrequência de alta } \\
\text { potência associada ao } \\
\text { ultrassom focado, com } \\
\text { um sistema de } \\
\text { resfriamento na } \\
\text { ponteira) }\end{array}$ & $\begin{array}{c}\text { Esse aparelho associa ultrassom e radiofrequência para } \\
\text { aquecer os tecidos, promovendo a regeneração das fibras de } \\
\text { colágeno, quebrando as células de gordura, melhorando a } \\
\text { circulação e drenando toxinas e líquidos. }\end{array}$ \\
\hline $\begin{array}{l}\text { Velashape II } \\
\text { (ação sinérgica da } \\
\text { radiofrequência } \\
\text { bipolar, led } \\
\text { infravermelho, } \\
\text { massagem mecânica e } \\
\text { vácuo pulsado) }\end{array}$ & $\begin{array}{l}\text { Além de estimular a produção de colágeno, ele trata o FEG em } \\
\text { qualquer grau e combate a flacidez moderada. Ele alia os } \\
\text { benefícios da radiofrequência, do infravermelho e da } \\
\text { massagem, ativando a circulação e melhorando os contornos } \\
\text { da pele. }\end{array}$ \\
\hline
\end{tabular}

Fonte: Sahd, 2019, p.56-57.

Para avaliar os efeitos da terapia por ondas de choque nos septos fibrosos de mulher brasileira, foi realizado um estudo experimental, 
randomizado, controlado e cego. Participaram 20 mulheres com FEG na região glútea (grau III), as quais foram avaliadas pré e pós tratamento através de protocolo de avaliação do FEG, questionário de avaliação da qualidade de vida, perimetria na circunferência glútea, plicometria da região glútea, peso corporal, registros fotográficos e exame de ultrassonografia na região glútea. As participantes foram divididas em 2 grupos: grupo de tratamento (GT) e grupo controle (GC) para receber a terapia através do equipamento D-ACTOR $200{ }^{\circledR}$ da marca Storz Medical AG (Tägerwilen, Switzerland). O GT recebeu a terapia por ondas de choque, mas o GC recebeu apenas a massagem vibratória. Utilizou-se como parâmetros a intensidade de 3,5 bar, frequência $21 \mathrm{~Hz}$ e dose de 1.500 pulsos por glúteo. Ambos os grupos foram submetidos a 6 sessões, uma vez por semana, com duração de 30 minutos. O estudo resultou em redução significativa da camada de gordura e dos septos com FEG e melhora na aparência do FEG e na qualidade de vida das participantes (Maia, 2018).

A terapia combinada é outra possibilidade de tratamento nas disfunções estéticas corporais, como o FEG, mas ainda há carência de estudos. Uma pesquisa prospectiva foi realizada de abril a dezembro de 2011, com 21 voluntárias, com fototipos de II a V e na faixa etária entre 24 e 39 anos. O estudo objetivou demonstrar a eficácia e segurança dessa modalidade terapêutica. As participantes foram avaliadas antes e após oito sessões de tratamento através de exames laboratoriais de colesterol total, triglicérides, creatinina, glicemia de jejum, TGO e TGP, peso, medida da circunferência abdominal e grau de satisfação. O tratamento utilizou a terapia combinada por ultrassom cavitacional, radiofrequência multipolar, endermologia e LED com sistema pneumático. Foram realizadas oito aplicações com duração de aproximadamente 40 minutos e com intervalo semanal. As voluntárias não apresentaram quaisquer sintomatologias sistêmicas (mal-estar geral, sintomas gastrointestinais, circulatórios, otológicos ou neurológicos) e nem alterações nos exames laboratoriais e nem houve sinais de queimadura. Em média, elas perderam $1,62 \mathrm{~kg}, 2,85 \mathrm{~cm}$ de redução na medida da circunferência abdominal e grau 6,83 na escala de avaliação de satisfação com o tratamento. A terapia demonstrou ser segura e eficaz para o tratamento tanto da gordura localizada e quanto do fibroedemageloide (Filippo \& Júnior, 2012).

Pode-se constatar que a evolução tecnológica com o advento de equipamentos com terapia combinada de ultrassom e radiofrequência; radiofrequência, led infravermelho, massagem mecânica e vácuo pulsado; laser de diodo aliado a massagem; ultrassom e correntes elétricas têm aumentado as possibilidades de tratamento com resultados clínicos mais rápidos e expressivos. Todavia, há carência de pesquisas que permitam confirmar quais destas terapias combinadas 
seriam mais significativas, com resposta mais imediata e menor risco de efeitos colaterais.

\section{CONSIDERAÇÕES FINAIS}

As pessoas têm procurado melhorar a aparência através de tratamentos estéticos e vários procedimentos têm sido utilizados e muitos envolvem os recursos eletroterapêuticos. $\mathrm{O}$ estudo investigou o resultado de alguns tratamentos recomendados para o fibroedemageloide. A carboxiterapia consegue reduzir o grau de FEG e melhorar a organização das linhas fibrosas e reduzir o tecido adiposo entre a pele e os músculos nas regiões tratadas com resultados comprovados por ultrassonografia. Já a radiofrequência melhora o tônus da pele, diminuindo o seu aspecto ondulado, aumenta a espessura dérmica e reduz o número de herniações do tecido subcutâneo. Os resultados da radiofrequência também foram comprovados pela análise das imagens ultrassonográficas. A terapia por ultrassom foi a que teve o resultado mais modesto, mesmo quando associado a cosméticos. A terapia extracorpórea por ondas de choque resulta em diminuição significativa da camada de gordura e dos septos com FEG, assim como as terapias combinadas de radiofrequência, led infravermelho, massagem mecânica e vácuo pulsado.

\section{AGRADECIMENTOS}

Agradecemos a revista PubSaúde pelo incentive a publicação e divulgação de estudos científicos.

\section{REFERÊNCIAS}

Afonso, J. P. J. M., Tucunduva, T. C. M., Pinheiro, M. V. B. \& Bagatin, E. 2010. Cellulite: a review. Surgical Cosmetic Dermatology, 2(3), 214-219.

Albrecht, L. P., Botti, L. S., Bonfanti, G., Costa, D. H. \& Deuschle, V. C. K. N. 2019. Tratamento do fibroedemageloide: uma revisão sobre o uso do ultrassom e dos ativos cafeína e centella asiática. Anais do $6^{\circ}$ Congresso Internacional em Saúde - Vigilância em Saúde: Ações de Promoção, Prevenção, Diagnóstico e Tratamento, UNIJUÍ, RS, Brasil. Recuperado em 5 setembro, 2019, de https://scholar.googleusercontent.com/scholar?q=cache:abC2bL3IruEJ:schol ar.google.com/+ultrassom+\%2B+celulite \&hl=pt-BR\&as_sdt=0,5.

Bacelar, V.C. F. \& Vieira, M. E. S. 2006. Importância da vacuoterapia no edemageloide. Fisioterapia Brasil, 7(6), 440-443.

Barata, J. 2015. Os mitos na saúde e na doença. Lisboa, PT: Verso de Kapa.

Bergesch, D. P. 2019. Análise mecânica do comportamento elástico efeitos clínicos da bandagem elástica adesiva sobre a celulite. Dissertação de mestrado, Universidade La Salle, Canoas, RS, Brasil. 
Bertozzo, R. P. E. 2016. O efeito midiático da celulite: um estudo em sites de beleza. Anais Sociedade Brasileira de Estudos Interdisciplinares da Comunicação XXXIX Congresso Brasileiro de Ciências da Comunicação, Intercom, SP, Brasil. Recuperado em 5 setembro, 2019, de http://portalintercom.org.br/anais/nacional2016/resumos/R11-0461-1.pdf.

Borges, F. S. \& Scorza, F. A. 2016. Terapêutica em estética: conceitos e técnicas. São Paulo, SP: Phorte.

Bosi, P. L. 2018. Técnicas aplicadas à estética corporal. Londrina, PR: Editora e Distribuidora Educacional S.A.

Bravo, B. S. F, Issa, M. C. A., Muniz, R. L. S. \& Torrado, C. M. 2013. Tratamento da lipodistrofia ginoide com radiofrequência unipolar: avaliação clínica, laboratorial e ultrassonográfica. Surgical Cosmetic Dermatology, 5(2), 138-144.

Cappellazzo, R., Batista, C., Marcelino, D. A., Nonino, F., Machado, M. C., \& Yamazaki, A. L. D. S. 2015, novembro. A aplicação do ultrassom terapêutico no tratamento do fibroedema geloide. Anais do IX EPCC - Encontro Internacional de Produção Científica UniCesumar, RJ, Brasil. Recuperado em 5 setembro, 2019, de http://rdu.unicesumar.edu.br//handle/123456789/2417.

Cavaleri, T., Silva, J. S., Dias, C., Almeida, A. A., Pereira, V. K. \& Buava, R. C. 2017. Benefícios da raquiofrequência na estética. Revista Gestão em Foco, 211-239. Recuperado em 2 setembro, 2019, http://portal.unisepe.com.br/unifia/wpcontent/uploads/sites/10001/2018/06/032_beneficios_radiofrequencia.pdf

Christensen, M. S. 2014. A succesful topical therapy for cellulite. Surgical and Cosmetic Dermatology, 6(4), 349-353.

Coutinho, H. M. E. L. \& Bravo, M. P. 2018. Composição corporal. Londrina, PR: Editora e Distribuidora Educacional S.A.

Federico, M. R., Gomes, S. V. C., Melo, V. C., Martins, R. B., Lauria, M. C., Moura, R. L., Medeiros, A. G., Souza. I. A., Veltman, J. F., Barboza, G. S., Sá, T.M., Santana, A.A. \& Borges, F.S. 2006. Tratamento de celulite (Paniculopatia Edemato Fibroesclerótica) utilizando fonoforese com substância acoplante à base de hera, centella asiática e castanha da índia. Revista Fisioterapia Ser, 1(1), 6-10.

Filippo, A \& Júnior, A. S. 2012. Tratamento de gordura localizada e lipodistrofia ginoide com terapia combinada: radiofrequência multipolar, LED vermelho, endermologia pneumática e ultrassom cavitacional. Surgical Cosmetic Dermatology, 4(3), 241-246.

Guerreiro, M. V. C. 2016. Celulite: processo, produtos, mercado, Almada. Dissertação de mestrado, Instituto Superior de Ciências da Saúde Egas Moniz, Monte de Caparica, Almada, Portugal.

Guirro, E \& Guirro, R. 2004. Fisioterapia dermato-funcional: fundamentos, recursos, patologias (3a ed. rev.). São Paulo, SP: Manole.

Hexsel, D. M, Dal'forno, T. \& Hexsel, C. L. 2009. A validated photonumeric cellulite severity scale. Journal of The European Academy of Dermatology and Venereology, 23(5), 523-528.

Kede, M. P. V. \& Sabatovich, O. 2015. Dermatologia estética. Rio de Janeiro, RJ: Atheneu. 
Maia, R.R. 2018. Efeitos das ondas de choque extracorpórea no fibroedemageloide (celulite). Monografia, Universidade Federal do Rio Grande do Norte. Natal, RN, Brasil.

Mendonça, R. \& Ramires, I. 2016. Mesoterapia. Lisboa, PT: LIDEL.

Menezes, R. C., Silva, S. G. \& Ribeiro, E. R. 2010. Ultrassom no tratamento do fibroedema geloide. Revista Inspirar, 1(1), 9-13.

Pianez, L. R., Custódio, F. S.,Guidi, R. M., Freitas, J. N. \& Sant'Ana, E. 2016. Effectiveness of carboxytherapy in the treatment of cellulite in healthy women: a pilot study. Clinical, Cosmetic and Investigational Dermatology, 9, 183-90.

Querleux, B., Cornillon, C, Jolivet, O. \& Bittoun, J. 2002. Anatomy and physiology of subcutaneous adipose tissue by in vivo magnetic resonance imaging and spectroscopy: relationships with sex and presence of Cellulite. Skin Research Technology, 8(2),118-124.

Ramos, A. R. 2018. Métodos aplicados à estética corporal. Londrina, PR: Editora e Distribuidora Educacional S.A.

Sahd, C.S. 2019. Tópicos especiais em estética. Londrina, PR: Editora e Distribuidora Educacional S.A.

Sartori, D. V. B., Domeni, T. V., Dadamos, I. R., Ferreira, L. R. \& Cavalheiro, C. R. 2017. Verificação da eficácia da radiofrequência em mulheres com fibroedemageloide em região de glúteo. Revista Inspirar, Movimento e Saúde, 41, 12(1), 11-16.

Seeley, R. R., Tate, P. \& Stephens, T. D. 2011. Anatomia e fisiologia (8a ed.). Loures, PT: Lusociência.

Silva, R. S., Oliveira, F. V. B, Amorim, J. S., Soares, M. T. S, Silva, D. P. F, Sales, S. C., Melo, L. S. \& Machado, R. S. 2017. A viabilidade da terapia com dióxido de carbono no tratamento da lipodistrofia ginoide (celulite). Anais do II Congresso de Saúde Estética do Piauí - II ESTHETICS, Teresina, PI, Brasil. Recuperado em 5 setembro, 2019, de https://gpicursos.com/interagin/gestor/uploads/trabalhosfeirahospitalarpiaui/2b9cb383c306641c9962b5154adf19b0.pdf

Siqueira, K. S. 2014. Aplicação do ultrassom terapêutico no tratamento de lipodistrofia ginoide, Dissertação de mestrado, Universidade Tecnológica Federal do Paraná, Curitiba, PR, Brasil.

Souza, C. S. 2003. Infecções de tecidos moles: erisipela, celulite, síndromes infecciosas mediadas por toxinas. Medicina Ribeirão Preto Online, 36(2-4), 351356.

Terranova, F., Berardesca, E. \& Maibach, H. 2006. Cellulite: nature and aetiopathogenesis. International Journal of Cosmetic Science, 28(3), 157-67.

Treu, C., Lupi, O., Bottino, D., \& Bouskela, E. 2009. Parâmetros microcirculatórios e clínicos em pacientes com lipodistrofia ginoide tratadas topicamente com alho (15 ppM). Surgical Cosmetic Dermatology, 1(2), 64-69. 


\section{MINICURRÍCULO}

VICENTE ALBeRTO Lima BesSA Tecnólogo em Estética e Cosmética pelo Centro Universitário Celso Lisboa (2018), Graduado em Fisioterapia (1992) pela Universidade Castelo Branco, especialista em Fisioterapia Dermato-funcional pela Faculdade Unyleya (2019), atuando principalmente nos seguintes temas: estética corporal, estética facial, estética masculina e terapia capilar.

MARIA FÁTIMA DE SOUSA BESSA Graduada em Educação Física pela Universidade Castelo Branco (1989), graduada em Fisioterapia pela Universidade Castelo Branco (1996), especialista em Ginástica Médica pela Universidade Castelo Branco (1993) e mestra em Ciência da Motricidade Humana pela Universidade Castelo Branco (2000), professora da Prefeitura de Duque de Caxias e Professora da Prefeitura do Rio de Janeiro, atuando principalmente nos seguintes temas: estética corporal, estética facial e psicomotricidade. 